\title{
The Clustering Conditions for Managing Creative Tourism Destinations: The Alqueva Region Case, Portugal
}

\begin{abstract}
The paper discusses conditions and format of a cluster model to support the management of a potential creative tourism destination in a setting where regional cross-sectoral collaboration is lacking. Creative tourism development requires a flexible framework and healthy collaboration environment, more so when associated to resources shared by several stakeholders. This article focuses on the tourism potential of archaeological knowledge discovered during the environmental impact assessment of the Alqueva dam (Alentejo, Portugal). Interviews were conducted with 38 regional actors in the tourism and heritage sectors, as well as the dam developers and the companies responsible for archaeological interventions. Findings indicate that the lack of specific local policy addressing archaeological heritage hampers its potential use for tourism development, which is further aggravated by the absence of stakeholder communication and cooperation. A conceptual cluster model for the management of creative tourism destination based on heritage resources and other local resources is proposed.
\end{abstract}

Keywords: regional tourism cluster; EIA; archaeological heritage; creative tourism; Alqueva dam; Portugal.

\section{Introduction}

The minimization of the social and environmental impacts of large development projects has become common practice in most of the Western world countries. Concerning archaeological heritage preservation, this intervention is commonly referred to as 'rescue archaeology' and it is undertaken in order to record the archaeological sites that are threatened by industrial and urban expansion, mostly within the scope of Environmental Impact Assessment (EIA) studies. Once the sites have been studied and documented, construction works take place and as a consequence the archaeological sites are generally destroyed (Willems 2008). In this way, only the knowledge of the past and the history of the site and finds are preserved. However, due to the lack of legislation and management solutions, in the present day this cultural resource is merely contributing to the increase of grey literature, i.e., non-conventional and somewhat ephemeral publications (Renfrew and Bahn 2012). Moreover, resource controllers mostly know this to be a cultural resource and a potential resource for tourism (Saxena and Ilbery 2008). This is in part because the actors involved in the rescue archaeology intervention undertaken during the EIA of major construction works have no legal formal relation, and therefore feel no need to engage in communication with the tourism industry stakeholders, who could integrate the archaeological heritage into their sector.

From a tourism perspective, another key problem in this context is that the archaeological sites are generally destroyed after they have been studied. However, the immateriality of archaeological heritage should not impede its appreciation by tourists when examined in the light of creative tourism. In creative tourism, the value of the tourism experience lies in the interactive engagement of the tourist with cultural elements of a place. Creative tourism grows from conventional cultural tourism, by providing the opportunity for visitors to experience greater personal transformation, to the extent that it allows the consumer to develop their creative skills and to achieve a sense of self-realization (Richards 2011, Richards and Wilson 2006, Tan, Kung, and Luh 2013). In this sense, the knowledge obtained from the practice of rescue archaeology may be applied to promote an archaeological landscape which is based on place branding and storytelling experiences, as opposed to standard tours to archaeological ruins (Holtorf 2007, Pine and Gilmore 1999).

Despite its potential to operationalize this intangible archaeological resource, the development of creative tourism poses some challenges concerning destination management, which have not been given sufficient 
attention (Richards 2011). In creative tourism, both small and medium enterprises (SMEs) and tourists participate in co-creating the tourism experience (Binkhorst and Den Dekker 2009, OECD 2014). The role of SMEs is key in developing the image and identify of a destination, and their role is the focus of this paper. It is essential that tourism destination management is conducted not only by tourism and cultural authorities, but also that it provides a participative and multi-sectorial approach that fosters the cooperation of all public and private stakeholders in the planning process (Jamal and Getz 1995, Coccossis 2009, Ilbery and Saxena 2011, Hager and Sung 2012, Le Blanc 2010).

In order for tourism destination management to be effective, the development of creative tourism requires a flexible operational framework and a context that is conducive to dialogue and cooperation, resulting from the spontaneity embodied in the creative process and the creative class (Andersen and Kragh 2013, Florida 2002, OECD 2014). Such cooperation can occur when there is an established network of local actors who are involved at all stages of the development process, each in their own different way, and it is essential for the successful production of ideas, products, and experiences (Brennan and Dooley 2005, Chapain and Comunian 2009). Furthermore, this integrative approach may also favour sustainable tourism goals (Welford and Ytterhus 1998), enhancing rural tourism development, if participation and collaboration of local government and businesses involved in tourism take place (Wilson et al. 2001), and when the potential for developing the creative sector is seen as an element for regional competitiveness (Lindroth, Ritalahti, and Soisalon-Soininen 2007). This study is part of a project which focused on the tourism enhancement of the archaeological heritage discovered during the construction of the Alqueva dam, located in the Alentejo region (Portugal). Despite the physical loss of most archaeological sites, previous studies suggests that those archaeological sites may still be valuable for developing tourism experiences, insofar as they are approached in a creative way (AUTHORS 2014).

This is furthermore supported by the Portuguese tourism policy, which favours the development of thematic channels, including archaeology in Alentejo, and a model for cross-sector collaboration (Turismo de Portugal 2013). However, the optimal clustering framework for tourism enhancement of this specific archaeological resource is unknown.

A set of conditions is necessary to favour potential clustering development process. As to tourism clusters Iordache, Ciochina, and Asandei (2010) indicate five essential requirements for the development of tourism clusters, namely: the presence of competitive enterprises; natural and cultural resources and favourable geography; the presence of some local or regional key-stakeholders; diversity (heterogeneity) of stakeholders; and the existence of formal and informal relations among stakeholders. Each of these conditions needs to meet an array of sub-conditions on its own, in order that they can together contribute to the formation of a fruitful cluster. For example, as is the potential for collaboration and cooperation, which are both directly dependent on the type of social capital predominant in the local culture (McGehee et al. 2010). Concerning the Alqueva case under study, the predominant type of social capital and form of local cooperation has been analysed, with findings suggesting a culture of dependency and widespread lack of initiative, which point out to a need for strong leadership in order to improve communication and trust amongst actors (Gomes, Dias-Sardinha, and Ross 2016).

This study examines the Alqueva case study in light of the five requirements for cluster development, paying special attention at the integration of archaeological resources within a wider set of attractions.

The aim of this article is to identify and characterize the elements which may favour the clustering process, in order to support the development of creative tourism initiatives, based on cultural resources, and to provide guidelines for an operationalization of a destination management model for the case study. The study contributes to wider literature by a) attempting to handle the complexity involved in such matters and b) trying to make its findings useful in a non-academic, and more practical, applied manner. 
The study was supported: 1) by secondary data analysis related to regional public policy and organizations regarding tourism destinations' characteristics, and; 2) by the analysis of 38 semi-structured interviews with local and regional stakeholders of the tourism and cultural heritage sectors, in order to understand their perception regarding the tourism evolution and tourism public policy and the value of the archaeological heritage in the Alentejo region, as well as the degree of communication and potential of collaboration among local and regional actors and other clustering conditions, in accordance with Iordache, Ciochina, and Asandei (2010). The paper that follows first presents a summary of research produced on clustering conditions for tourism destination management. Next, the case study and the regional tourism policies of Alentejo are presented, followed by the description of the research design and the presentation of results. A discussion is carried out of the findings, and an aspirational creative destination management model is presented. Finally conclusions are drawn to close the paper.

\section{Clustering Conditions and Tourism Destination Management}

Several authors have linked SME's cooperation to the encouragement and openness of stakeholder participation in the process of planning and decision-making (Kasemir, Jaeger, and Jager 2003, Hager and Sung 2012, Pearce 2014); to participative and multi-sectorial approaches fostering cooperation of public and private stakeholders in planning processes (Jamal and Getz 1995, Coccossis 2009, Le Blanc 2010, Ilbery and Saxena 2011), and to the development of territorial strategic networks (Eklinder-Frick, Eriksson, and Hallén 2011), and in clusters (Porter 1998, Alberti and Giusti 2012).

Tourism development in rural areas contributes to the benefit of the two types of SME's: those directly involved in tourism (e.g., attractions and hotels), and those indirectly involved (e.g., grocery shops and even farms) (Wilson et al. 2001). However, according to the same authors, this can also have disadvantages for rural areas, e.g., by putting rural communities in competition against one another. Cross-sectorial collaboration is therefore needed to achieve potential regional development on the basis of tourism.

Porter $(2000,15)$ defines clusters as being 'the geographic concentrations of interconnected companies, specialised suppliers, service providers, firms in related industries, and associated institutions (e.g., universities, standards agencies, trade associations) in a particular field that compete, but also cooperate'. The success of the cluster model is based on the cooperation effort that an agglomeration structure stimulates amongst companies and stakeholders who normally would not contact each other in the value chain of a product, service, or resource (Erkus-Ozturk 2009, Nordin 2003, Plummer et al. 2005). Furthermore, in strategic terms, the cluster model allows for a participative approach to regional development, encouraging the involvement and considering the needs of SMEs in tourism planning and policy development for the sector (Komppula 2014, Castellani and Sala 2010, Wang and Ap 2013). Therefore a joint initiative created for the development of a regional tourism cluster may include national, regional, and local authorities, all of which contribute to devise an action plan which supports the development of tourism products and experiences that are associated with a shared resource (Nordin 2003, Pearce 2014). Moreover, the quality of a tourism destination is also improved by bringing coherence to a territory, in the form of theming and creating favourable conditions for the knowledge transfer between members of the network forming a potential cluster (Tallman et al. 2004). In addition, in rural areas, networking and clustering can contribute to diminish those negative effects of geographic dispersion of tourism that often characterises these rural territories e.g., help to curtail seasonality, one of the major problems that affects the tourism industry (Novelli, Schmitz, and Spencer 2006). At the organisational level, evidence suggests that networking and clustering can increase the competitiveness of tourism sector SMEs (Novelli, Schmitz, and Spencer 2006, Porter 1998, 2000, Spencer et al. 2009, Pearce 2014). Clustering, according to Weidenfeld, Butler, and Williams (2010) is "understood as the process of optimising gains from economies-of- 
scale and of-scope, as a result of reductions in the average costs of member firms (Michael 2007). Clustering produces a range of synergies which may enhance the growth of market size, employment and product (Michael 2007), and in the context of tourism may create a localised chain, whereby a few sub-products 'produce' the overall tourism product."

For the present study, the question of how clusters develop is of particular interest. According to Jackson and Murphy (2002), tourism clusters are a form of industrial cluster based on Porter's (1998) cluster theory. Alberti and Giusti (2012) described the development of the Motor Valley cluster in Italy, whereby an informal network was formed among multiple actors, from tourism SMEs through to museums and auto plants, which evolved into a product club, from which emerged the cluster. For these authors, a product club is an informal grouping of members from different sectors, usually SME, who all share an interest in the commercial exploitation of a collective resource. These groups are formed in order to create new products or to improve existing products, based on the collective resource, regardless of the individual members' connection to the resource (Alberti and Giusti 2012, Plummer et al. 2005, Gomis et al. 2010).

Furthermore, during the emerging phase of the cluster's life cycle, it is possible to observe a shared vision among the companies in the territory, whose communication may be conditioned by their own heterogeneity. In this vein, Menzel and Fornahl $(2010,213)$ argue that the implementation of a cluster depends on the occurrence of focal points of activity, defined as having a 'high density of interconnections around specific topics'. Nonetheless, some issues may arise during the process of networking and the further development of clusters. For instance, the ambiguity of the cluster concept frequently leads to multiple interpretations concerning the nature and number of members required to form a cluster, or the geographical extent of the area covered (ErkusOzturk 2009). Furthermore, the development and growth of networks and clusters depends on multiple variables. The collaborative process is necessarily tied to the community's social capital and specific cultural conditions of bonding, bridging and linking capital. Elements such as ignorance, distrust, and autocratic social cultures must be considered before any thematic networks, product clubs, or clusters can emerge (EklinderFrick, Eriksson, and Hallén 2011). These elements can hinder the communication and networking process, which are essential for cluster development, and are widespread in the Portuguese socio-cultural context (Gomes, Dias-Sardinha, and Ross 2016). Social capital dynamics in the region have been previously examined by AUTHORS (2016). In sum, strong community cohesion was observed, associated to a strong sense of ownership and self-interest. Findings illustrated the lack of bridging ties in the studied region and a far greater focus on product specialization than on integrated offer, which is aggravated by unwillingness to innovate. It becomes clear that lack of bonding in these communities affects the implementation of value co-created tourism experiences, making it clear that conditions must be created in order to ensure that both active participation and free information flow are rewarding and reliable (AUTHORS 2016). Thus it is necessary to improve trust and reduce symptoms of autocratic culture, such as the absence of bridging capital social at the local level. Such an approach, supported by a cluster model, may enhance the collaborative processes of tourism destination management at the regional level.

\section{Case study}

This article is part of a project that aims to verify how the archaeological knowledge recovered during the construction of a large infrastructure can be valued and improve tourism development in the affected region. The case in point is the Alentejo region, a tourist destination which underwent structural geographic modifications associated with the construction of Alqueva dam and its irrigation system, and that ultimately influenced tourism policy for the region.

We now present a brief contextualization of the case study, before moving on to the results of a set of semistructured interviews to the stakeholders. 


\section{Context}

\section{The Alqueva Multi-Purpose Dam and Archaeological Intervention}

Concluded in 2002, the Alqueva multi-purpose dam created the largest artificial lake in Europe, providing irrigation to 120,000 hectares of farmland in the Alentejo region. The Alqueva global irrigation system is composed of 69 small dams, reservoirs, and weirs, together with $382 \mathrm{~km}$ of a primary network that connects the all dams of the system, 1,620 km of secondary network pipelines to take the water to the farmers' land, 47 pumping stations, 6 mini hydroelectric stations, and one photovoltaic power station. In summary, the multipurpose Alqueva development is primarily an agricultural project (EDIA 2013). The EIA undertaken in this huge expanse of territory revealed empirical archaeological data which enhanced our knowledge about the ancient human occupation of the territory (Figure 1) (Valera 2013).

Insert fig 1 - Figure 1. Density of Neolithic ditched enclosures registered in the Alentejo region. (Source: Valera, 2013)

The study was undertaken in three counties of the Alentejo, namely: Serpa, Vidigueira, and Moura, which surround two important archaeological sites dating from the Bronze Age: the Outeiro Alto 2, and the Sobreira de Cima burial grounds. Both sites reflect in an exemplary manner the result of the possible (in)tangibility of rescue archaeology: the Outeiro Alto 2 grave is on an artificial island inside an irrigation block, which prevents access to the site (Figure 2); and the Sobreira de Cima grave is located near a high-voltage electrical substation, which is unsuitable for the presence of visitors or tourists. In both cases, the findings remain in-situ and are closed off to the public, so all that is left is the historical knowledge obtained from the study of these sites.

Insert fig 2 - Figure 2. Aerial view of the Brinches irrigation block / Outeiro Alto 2 necropolis (Source: EDIA)

The public construction developers responsible for the Alqueva project, the EIA study, and the excavation of both sample sites are respectively: the Alqueva dam developers - Empresa de Desenvolvimento e Infraestruturas do Alqueva, SA (EDIA), and Redes Energéticas Nacionais (REN), a national energy transportation company. A third company - Estradas de Portugal (EP), a national motorway developer - is also involved in some linear works in the Alqueva region.

EDIA, besides being responsible for managing the Alqueva dam and irrigation system, has established some of the most valuable assets for tourism, such as the Museum da Luz, and the Noudar Nature Park. EDIA is also the organisation that chairs the Regional Tourism Board's General Assembly, which reveals the company's importance in the organisational structure of the Alentejo's tourism. Nonetheless, an analysis of the developer's social and environmental responsibility policies in their annual sustainability reports reveals no explicit written interest in the touristic valuation of archaeological knowledge obtained during EIA.

\section{Portuguese Tourism Policy and Alentejo's Business Environment}

Globally, the business environment of Alentejo is relatively poor, with competitive levels below the national average (INE 2014). Nevertheless, some Portuguese economic groups have been attracted to the region since the construction of the dam, namely: 1) Amieira Marina boat rentals, which has assumed a central place in regional tourism; 2) the SAIP group, which is associated with Esporão, SA (a large wine and olive oil producer). The Esporão wine producer, besides owning the largest vineyards in the country, has also developed interesting projects related to environmental sustainability and archaeological heritage, e.g., by sponsoring research on the Perdigões archaeological site that was found within the perimeter of their vineyards; 3) the Dark 
Sky Alqueva star tourism project, which is still at an early stage of development, but has achieved some success and is growing steadily.

The National Strategic Plan for Tourism (Turismo de Portugal 2007, 2013) is the foundation of the current Portuguese tourism policy, which has established five main Regional Tourism Boards to govern the sector. In addition, six Special Region Tourism Boards were established in 2008 to administrate specific regions with outstanding potential, one of which is the Alqueva Lake. This decision was justified at the time by the potential and unique resources found in the region, more specifically: the Great Lake of Alqueva (the reservoir created by the dam); proximity to Évora, a UNESCO World Heritage Site; and the prospect of large Residential and Golf luxury resorts to be implemented on the banks of the Great Lake. These luxury resorts were regarded by the Portuguese government as being essential for the development of the region, and as such were called National Interest Projects (NIP). However, the economic crisis (2008 onwards) led to the postponement of the NIP projects, and in 2012 the public reform of the tourism sector dictated the extinction of the six Special Region Tourism Boards. The Porter Report (1994), which is a reference document for the national economic policy, briefly refers to a regional tourism cluster in Alentejo (Monitor Company 1994, 55). However, it is not currently operational, neither formally recognised.

As a result, the regional tourism industry is still strongly associated with the traditional Alentejo identity that existed prior to the dam's construction, that is, it is centred on products related to cultural and rural tourism, such as wine and food, and heritage tourism (Dias-Sardinha and Ross 2015). An exception is the emergence of some innovative tourism projects that have achieved a certain degree of success, such as the Amieira Marina, a boat-house rental business, and the Dark Sky Alqueva, a project which exploits the night sky as a product.

\section{Methodological approach}

\section{Interviews with Tourism and Heritage Actors and Construction Developers}

This study was based on 38 semi-directed interviews held personally and locally with regional and local tourism and heritage actors and construction developers. In total, between February and August 2013, interviews were carried out with 35 actors of the tourism and cultural heritage sectors, and 3 construction developers.

All interviews were carried out in Portuguese at the interviewee's workplace, and were recorded for a total of 30 hours and 40 minutes and were later transcribed onto paper. MAXQDA 11 (VERBI Software 2012) was used for coding and analysing the collected data. The categories that resulted from the interpretation of the data were obtained through a process of thematic coding, loosely based on the interview topics (Saldaña 2013). Then the aggregate results according to these categories were used to support an organised analysis, taking into account the requirements for the formation of a cluster, in accordance with Iordache, Ciochina, and Asandei (2010).

The tourism and heritage actors were randomly selected. To ensure optimal selection, the Andalusian tourism cluster map (Lastra-Anadón et al. 2011) was used, assuming an identical structure for a potential future tourism cluster in this area of Portugal.

The actor sample includes 5 municipal and regional government bodies, 4 cultural heritage institution managers, 5 tourism governing bodies, 18 private businesses and commercial associations, and the directors of the 3 professional schools that include tourism degrees in their curricula. Three of the interviewees represented two different institutions. Furthermore, interviews were also carried out with the representatives of the 3 public construction developers associated with the Alqueva dam region - EDIA, REN and EP.

The aim of the semi-directed interviews carried out with the tourism and heritage actors was to understand their perception regarding:

i) The archaeological works that were undertaken during the main dam construction, and the tourism potential of the knowledge obtained; 
ii) The degree of communication and networking amongst stakeholders and other clustering elements relevant for regional tourism management.

With regard to the construction developers, the aim was to understand:

i) Their views and interest in the tourism enhancement of the archaeological knowledge obtained from the EIA;

ii) How the developers expect to contribute to a hypothetical tourism enhancement project, and what advantages and benefits they expect to obtain.

\section{Results}

Following data analysis, the data was organised into four main themes: i) Tourism and heritage actors perception of archaeological heritage's value; ii) (Un)awareness of the archaeological finds of Alqueva; iii) Construction developers' perception regarding tourism enhancement; and iv) Stakeholder communication and collaboration and leadership potential. Each of these themes is presented below with illustrative quotes.

\section{i) Tourism and Heritage Actors Perception of Archaeological Heritage's Value}

Concerning the perceived value of archaeological heritage, in general, many tourism and heritage actors interviewed stated that archaeological heritage is a valuable resource for the Alentejo's regional tourism industry. Furthermore, many participants argued that archaeology should work as a complement to the current supply, rather than a standalone tourism product.

If it is part of a good route... with other products... and is well integrated, then it would be viable because there is tourism demand for that. (...) An entirely archaeological experience would have to be for experts, I think, for someone who liked it and who is an expert. (interview \#25 - craftsman)

\section{ii) (Un)awareness of the Archaeological Finds of Alqueva}

With the exception of some experts and archaeologists that followed the archaeological interventions, a large number of the tourism and heritage actors were unaware of what had resulted from that intervention.

I do not know if there is exactly that awareness, at least not by the general public I don't think so. (...) And much less at that level that you are speaking. (interview \#29 - director of professional school)

No one here talks about it, as no one knows, no one informed us. Those who know are the employees of EDIA, just a few archaeologists and no one else. (interview \#27 - restaurant owner)

It is clear that, despite archaeology being perceived as an important tourism element, the lack of awareness by the tourism and heritage actors about the local archaeological findings prevents them from realising its specific tourism potential. Various respondents expressed their interest in learning about the results.

One of the first things I would need to know is what was found, and what we could do, to go to the terrain and learn and also have the training to understand what was found, how important it is, and all of these issues. I think this is a first step that would open the possibility for tourism companies to create their own routes and their own ways of working with the heritage that has been identified. (interview \#8 - tourism businessman) 


\section{iii) Construction Developers' Perception Regarding Tourism Enhancement}

The representatives of the 3 construction developers interviewed expressed their enthusiasm in seeing that the archaeological knowledge obtained in the EIA procedure may be useful for the development of tourism initiatives. All three stated that such initiatives are in line with their corporate social responsibility policies, although their sustainability reports are unclear on this matter. However, they found it hard to point out exactly how they could contribute in practice to such an endeavour and what benefits could result. Each representative's results are referred to in more detail below.

The representatives of EDIA expressed interest in a regional tourism project that could create an umbrella for the company's assets in the region, explaining that each of these assets has a low individual impact and that themed collaborative promotion could reduce this problem. The developer is aware of the public's interest in the history of the Alqueva dam, and is therefore keen on developing a digital tourism guide that could provide information not only about archaeological aspects, but of all the region's heritage, and 'tell the whole story of the dam'. Concerning the dissemination of the archaeological knowledge in their possession, the interviewees stated that a volume of monographs with the archaeological results was published in 2014. The company representative interviewed is aware that creative tourism enhancement of archaeological knowledge could provide an opportunity to obtain some return (e.g., through reputation benefits) from the investment required for the EIA.

The representatives of REN were interested in the potential opportunities presented by a creative tourism approach to archaeological knowledge, stating that it had the potential to 'leverage an economic cycle' that could ensure the tourism project's sustainability in the medium and long run. As they argued, one of the current problems of archaeological interventions within EIA is that such interventions generally brings no benefits for the developers. Therefore, they argue for the need to develop platforms that can facilitate the disclosure of archaeological knowledge.

The representatives of EP affirmed their company's interest in taking part in tourism projects, stating that the company could contribute to the dissemination of archaeological heritage by implementing specific road signage and by making the company's GIS platform available. This platform could host, for example, a virtual museum of the heritage destroyed during the construction works.

\section{iv) Stakeholder Communication and Collaboration and Leadership Potential}

The interviews revealed a clear lack of communication among the different actors able to intervene in the tourism enhancement of archaeological knowledge derived from the EIA. City Councils often communicate with all the other actors.

[Communication and cooperation is] sometimes better, others worse, it depends on the political cycles. But objectively this is a region which needs this because there is little critical mass, people necessarily have to come together and think. That still happens, a little bit. (interview \#9-director of heritage managing organization)

However, other stakeholders, such as archaeologists, tourism businesses, and construction developers, occasionally communicate with each other within their sector, but rarely do so with external actors. For example, construction developers do not usually contact local tourism SMEs, as the following quote shows: If you ask me what EDIA is currently doing in terms of archaeological heritage enhancement of the Alqueva, I confess that I do not know. However... we are going to start looking at the Alqueva more intensely and then it will make sense to strengthen relations at this level with EDIA. (interview \#34tourism authorities representative) 
Archaeologists are also required to facilitate the process of communication and knowledge exchange, as it is they that have the power and intellectual capital to synthetize archaeological knowledge to non-specialists:

'There is a need to have this information treated scientifically, is there not? (interview \#16 - tourism authorities representative).

Various participants mentioned the need for someone to lead the process of archaeological knowledge enhancement, coordinating all stakeholders and creating the conditions for a collaborative action to successfully take place.

I don't find it unreasonable to enhance our archaeological heritage, but there must be an entity that takes the lead... First of all, there must be an institution that can lead the way. (interview \#6 - wine producer)

Even if an individual person is full of ideas, the project remains utopian if there is not some kind of interrelational support. (interview \#3 - local administration representative)

In this sense, some organisations that could assume a leadership role were suggested, such as the Regional Tourism Board, or a private company. Others argued that it could be EDIA, or a joint venture that included EDIA and the City Councils. Some respondents argued that although the City Councils play a key role in the region, they should not take the lead due to difficulties concerning inter-council cooperation.

Finally, concerning formal and informal interrelations and the potential for leadership among stakeholders, an interesting example can be found among those interviewed is the Dark Sky Alqueva. The project has developed a small network that comprises several institutional players and SMEs that work together to explore the starry sky, which is a common resource. Managed by one of the entrepreneurs, every network member develops their business autonomously, based on the central theme, thus contributing to consolidate a product and brand in the territory and the building of a shared vision for the future.

In sum, data collected in the interviews shows that local actors: i) acknowledge the significance of archaeological heritage in tourism industry; ii) have difficulty accessing new archaeological knowledge produced; and iii) express the need for someone to take initiative and lead the process of knowledge dissemination and tourism enhancement of archaeological knowledge. The following discussion examines the data collected in light of literature on cluster development.

\section{Discussion}

From the data collected we found that there is a great imbalance regarding the knowledge of resources among resource controllers and the tourism / heritage actors. Furthermore, there is no established collaborative network in Alentejo that includes tourism and heritage actors, construction developers, and other stakeholders. Therefore, there is an absence of short to medium term conditions to encourage the kind of management necessary for the development of an archaeological tourism cluster.

An agglomeration or clustering model that starts when archaeological resources are first assumed to be relevant may provide a way to facilitate the exchange of information (Pearce 2014) and further collaboration. A creative 
approach to archaeological heritage may inform a focal point of activity and permit a high density of interconnections around specific topics supported by cross-sectorial collaboration (Menzel and Fornahl 2010). In this sense, the results of this study are cross-examined in the light of the elements that characterise a cluster development, in line with the findings of Iordache, Ciochina, and Asandei (2010) and Saxena and Ilbery (2008). The analysis aims to increase our understanding about the required conditions for the development of a potential thematic "product club", followed by a cluster associated with Alqueva's archaeological heritage. Accordingly, the requirements for cluster development are discussed next:

\section{i) Natural and Cultural Resources}

The construction of the Alqueva dam generated new resources in the region, namely the reservoir and the archaeological knowledge obtained from the EIA. Firstly, the reservoir provides irrigation and therefore serves agricultural purposes, but it also offers conditions for related lake leisure tourism. Secondly, despite the destruction of the tangible heritage, archaeological knowledge can be of value to the tourism industry, provided that it is used in a creative way. The viability of this kind of product is based on the brand value that archaeology holds in popular culture (Holtorf 2007). This is in agreement with several authors who argue that the intangibility is as much a disadvantage as an opportunity for tourism, particularly when orientated toward the development of creative tourism experiences (Richards and Wilson 2006, Waitt 2000). In this way, archaeological knowledge can feed the tourist's imagination and can provide the destination with a story to tell, from which creative experiences can be developed (Pera 2014); AUTHORS, 2014). In the case of Alentejo, the archaeological knowledge generated from the EIA can provide new ideas and business opportunities for the tourism sector.

However, data collected clearly indicate that the tourism potential of Alqueva's archaeological knowledge at the moment is purely conceptual, as tourism stakeholders are unaware of its existence. Nevertheless, if successful exchange of information between all actors and sectors is assured and existing leisure and cultural tourism absorbs new creative archaeological tourism experiences, sufficient resources will become available for the growth of a regional tourism cluster.

\section{ii) The Diversity of Stakeholders}

With regard to the heterogeneity of the stakeholders, findings suggest that there are several players in the archaeology-tourism axis in Alentejo with different interests in tourism development, namely:

1) the resource controllers (Saxena and Ilbery 2008) who exert control over the archaeological knowledge:

- The construction developers responsible for the EIA, for which they are obliged to create the collective resource. In addition to the limitations in disseminating these results, they are faced with a need to make the most of their assets and to contribute to local socio-economic development. This fits the findings, given that they agree that tourism enhancement of archaeological knowledge can provide an opportunity to obtain some return on investment that the EIA requires.

- The archaeology companies and experts hold the scientific understanding of the archaeological knowledge. The disclosure of this knowledge is currently confined to academia and to some published monographs, but there is a growing interest by the scientific community to develop new channels to bring this discipline closer to the greater public (Holtorf 2007). Interviewed experts argued that the archaeological findings in Alqueva enrich our view of the region's past which, allied to the already significant role of archaeology in the region's tourism industry, could provide a window of opportunity.

2) and the tourism and heritage actors, who are knowledgeable about the local socio-economic reality and tourism dynamics: 
- As we found in the study, the public policy tourism stakeholders of Alentejo have the political interest and socio-economic power to influence the sector at both the local and regional level. These stakeholders can contribute at the regulatory, strategic, and planning level for the sector, as well as through political action and potential funding, and could design the framework within which private actors can develop their business, as confirmed by the respondents,-The National Strategic Plan for Tourism (Turismo de Portugal 2007, 2013) being one example.

- The private tourism sector (SMEs) can offer the local perspective and has the ability to transform and adapt archaeological knowledge according to demand. Currently, these SMEs are responsible for the development of products and experiences and, by receiving consumer feedback, for keeping the knowledge about the local tourism reality up to date. Dark Sky is a good example which shows that tourism companies can come together and collaborate on developing a tourism product based on a resource with no previous history in the destination (night sky observation).

\section{iii) The Competitiveness of the Business Environment}

Of the five requirements identified for cluster development, the one which is missing in our case study region is the presence of competitive enterprises. As our study shows, competitivity is limited to agribusiness SME's. However, according to the national tourism policies, the development of tourism initiatives based on local and regional resources, including archaeology, is encouraged for the growth of tourism in Alentejo. This fits the findings. For example, the Alqueva dam developers are aware that tourism enhancement based on the archaeological knowledge could provide an opportunity to obtain some of the return on investment that the EIA required. Furthermore, we also found some competitiveness potential that already exists in Alqueva, for example: the Dark Sky, which, as in the case of rescue archaeology, also makes use of a partially (in)tangible resource, which requires somewhat a creative approach to the design of the touristic product. The company also organises some night sky gazing sessions from near megalithic cromlechs. This is in line with what Prentice and Andersen (2007) see as being essential at the destination level, which is to find the link between the destination's resources and the needs of tourists.

In summary, given the business opportunities created by the Alqueva Great Lake, as well as the government's stated interest in capitalising the investment, further long-term positive developments can be expected concerning an increase in the number of firms with a competitive edge in the region.

\section{iv) The Presence of Key-Stakeholders and Leaders}

From the study we learn that there are stronger practical perspectives concerning collaboration to support the development of a creative form of archaeological tourism. However, there was no indication of what resources each entity might contribute to, nor what would be sought from these collaborations.

Accordingly, based on the findings of both stakeholder groups, there are key-actors that have some power to stimulate the regional economy. More specifically, those few companies could be identified which may potentially play an important role in the development of tourism initiatives are: The Amieira Marina (which provides boat rentals, an extremely popular product and postal-image of local tourism), Esporão (wine and olive oil), Dark Sky (sky tourism), and EDIA. The second company, Esporão, is recognized at the national level for its food products, and also for its local action with regard to support for archaeological exploration and biodiversity. It is undoubtedly a stakeholder with leadership power within a collaborative cross-sectorial framework. Dark Sky is an excellent example of cross sectorial collaborative leadership and initiative, and it is open to participation. EDIA should always be involved in any activity associated with the Alqueva, given that its goal is Alqueva's development and it has a declared interest in enhanced knowledge heritage. 


\section{v) Formal and Informal Relationships}

At a regional level of Alentejo, a tourism development project that relies on a collaborative (sectorial and crosssectorial) framework may be difficult to implement, given the widespread lack of communication that was identified. Likewise, it may also be difficult to convince tourism entities and other of the value of joining forces for cooperation. If "the ability to cooperate and communicate is a prerequisite for creativity" (Lindroth, Ritalahti, and Soisalon-Soininen 2007), current social characteristics, such as ignorance, distrust, and autocratic social cultures, found in Alqueva region(AUTHORS, 2016), may actually hamper the creation of a focal point of activity (Menzel and Fornahl 2010) centred on the archaeological heritage and creativity. These issues must be taken into consideration for the understanding and enhancement of the necessary conditions before one or more thematic networks, product clubs, orclusters can emerge (Eklinder-Frick, Eriksson, and Hallén 2011). Hence, all these elements can hinder the communication and networking process, which are essential for cluster development. In addition, these social traits may reduce local actors' willingness to participate in all stages of cluster development process, a fundamental requirement for the successful production of ideas, products, and experiences (Brennan and Dooley 2005, Jamal and Getz 1995, Chapain and Comunian 2009) in creative tourism.

Nevertheless, it is possible, as can be seen in the case of Dark Sky. Currently, the Dark Sky project fits the product club stage described by Alberti and Giusti (2012) for the cluster development process. It is a good example of cross-sectorial collaboration and competitiveness, together with a local strong leadership. On the other hand, given the prevailing culture of dependency and the lack of initiative present in Alentejo, strong leadership is necessary to improve communication and trust for the emergence of a clustering process in the region, and it is assumed that there must be a collaborative planning based on human, technological, organizational, and financial capital (Saturnino 2009). In addition, a long-term planning of tourism for the Alentejo destination is needed.

Furthermore, scholars argue that a tourism cluster's appeal as a whole is greater than the sum of the individual attractions (Dredge 1999, Weidenfeld, Butler, and Williams 2010). A creative tourism approach may enhance the destination at the greater level by encouraging tourist participation in small activities within the region that enable their creative expression, regardless of type of heritage attraction. In this sense, our findings lead us to suggest a potential cross-sectorial collaboration or a cluster archaeological creative framework for the Alentejo region with the following format (Figure 3).

Insert Fig 3 - Figure 3. Format of an emerging archaeological creative tourism cluster in the Alentejo region.

Thus, in the perspective that Alqueva's archaeological heritage can be disclosed and used as a valuable resource for tourism development, the marketing of the Alentejo region as an archaeological destination may be significantly enhanced (Blain, Levy, and Ritchie 2005). This would require the development of a thematic concept for the destination - an archaeological story, e.g. Creative Alqueva/Alentejo - founded on an agglomeration framework, such as a cluster that can facilitate the development of self-directed, yet interconnected activities in the region. Such a framework should be managed beyond the top-down logic of regulators, based on growing collaboration that includes the participation of SMEs in a bottom-up process, where each player continues to develop their business, supplementing it, and benefiting from archaeological knowledge in a way that can bring them a competitive advantage.

\section{Conclusions}


This study provides new empirical data and insights for a better understanding of the clustering conditions of creative tourism and its destination management. In particular, we learn that the high potential of the appreciation of intangible resources for the development of creative tourism initiatives, as recognized by resources controllers, can be greatly reduced if these features are unknown to tourism and heritage actors, given that the development of creative tourism implies a conscious effort, with participative and cross-sector collaboration in destination management. This finding informs us that the process of clustering, even though difficult, is potentially advantageous for the involvement of all those actors who can promote a participative development of the region, insofar as it integrates the needs of the interested parties, whether these come from the tourism, cultural heritage, or the environment sectors.

Locally, this study helped to increase awareness of the issue, in addition to suggesting a model of management for the tourist destination that could facilitate future planning. For example, the tourism enhancement of archaeological knowledge, if developed within an agglomeration framework or cluster, when collaboration and cooperation are planned, could contribute to an increase of tourism SMEs' competitiveness and could create opportunities for the construction developers to obtain added socio-economic benefits from the EIA. These are some essential conditions that could enhance a clustering process, which give rise to hopes of an adequate destination tourism local management framework.

With regards to the emergence of specific creative tourism, further research is necessary in order to understand the creative potential associated with the actors involved. That is, it is necessary to learn more about the local actor's creative potential and its application in developing cross-sectorial creative tourism experiences.

However, in the specific case of the Alentejo region, where cooperation is difficult, it would seem adequate to first implement a follow-up pilot project which could test the validity of the framework for collaboration (Gomes, Dias-Sardinha, and Ross 2016), contributing further to the aspirational cluster model presented here. Such a model should be crafted in a spirit of collaboration and should systematically analyse the elements that facilitate the collaboration of public and private stakeholders for a tourism development enhancement project which contributes to the dissemination of knowledge about the history of the Alentejo region and its crafts and local creativity. 


\section{References}

Alberti, Fernando G., and Jessica D. Giusti. 2012. "Cultural heritage, tourism and regional competitiveness: The Motor Valley cluster." City, Culture and Society 3 (4):261-273. doi: 10.1016/j.ccs.2012.11.003.

Andersen, Poul Houman, and Hanne Kragh. 2013. "Managing creativity in business market relationships." Industrial Marketing Management 42:82-85. doi: 10.1016/j.indmarman.2012.11.007.

Binkhorst, Esther, and Teun Den Dekker. 2009. "Agenda for co-creation tourism experience research." Journal of Hospitality Marketing \& Management 18 (2-3):311-327. doi: 10.1080/19368620802594193.

Blain, Carmen, Stuart E. Levy, and J. R. Brent Ritchie. 2005. "Destination Branding: Insights and Practices from Destination Management Organizations." Journal of Travel Research 43:328-338. doi: $10.1177 / 0047287505274646$.

Brennan, Attracta, and Lawrence Dooley. 2005. "Networked creativity: a structured management framework for stimulating innovation." Technovation 25:1388-1399. doi: 10.1016/j.technovation.2004.08.001.

Castellani, Valentina, and Serenella Sala. 2010. "Sustainable performance index for tourism policy development." Tourism Management 31 (6):871-880. doi: 10.1016/j.tourman.2009.10.001.

Chapain, Caroline, and Roberta Comunian. 2009. "Enabling and inhibiting the creative economy: The role of the local and regional dimensions in England." Regional Studies 44 (6):717-734. doi: 10.1080/00343400903107728.

Coccossis, Harry. 2009. "Sustainable development and tourism: opportunities and threats to cultural heritage from tourism." In Cultural Tourism and Sustainable Local Development edited by L. F. Girard and P. Nijkamp, 47-56. Surrey: Ashgate.

Dias-Sardinha, Idalina, and David Ross. 2015. "Perceived impact of the Alqueva dam on regional tourism development." Tourism Planning \& Development 12 (3):362-375. doi: 10.1080/21568316.2014.988880.

Dredge, Dianne. 1999. "Destination place planning and design." Annals of Tourism Research 26 (4):772-991.

EDIA. 2013. "EDIA S.A. - Histórico [History]." Last Modified May 28. http://www.edia.pt/edia/index.php/oempreendimento/historico.

Eklinder-Frick, Jens, Lars-Torsten Eriksson, and Lars Hallén. 2011. "Bridging and bonding forms of social capital in a regional strategic network." Industrial Marketing Management 40 (6):994-1003. doi: 10.1016/j.indmarman.2011.06.040.

Erkus-Ozturk, Hilal. 2009. "The role of cluster types and firm size in designing the level of network relations: The experience of the Antalya tourism region." Tourism Management 30 (4):589-597. doi: 10.1016/j.tourman.2008.10.008.

Florida, Richard. 2002. The rise of the creative class: And how it's transforming work, leisure, community and everyday life. New York: Basic Books.

Gomes, Ana Calapez, Idalina Dias-Sardinha, and David Ross. 2016. "The hierarchical gap: bypassing communication barriers to build collaborative processes for value co-creation in rural settings." In Meeting Challenges For Rural Tourism Through Co-Creation Of Sustainable Tourism Experiences, edited by E. Kastenholz, M. J. Carneiro, C. Eusébio and E. Figueiredo. Newcastle upon Tyne: Cambridge Scholars Publishing.

Gomis, Francisco J., David L. Lluch, José M. Civera, Asunción M. Torres, Margarita B. Mollá-Bauzá, África M. Poveda, Fermín C. Ríos, and Antonio M. Pedregal. 2010. "Wine tourism product clubs as a way to increase wine added value: the case of Spain." International Journal of Wine Research 2:27-34.

Hager, Mark A., and HeeKyung Sung. 2012. "Local Arts Agencies as Destination Management Organizations." Journal of Travel Research 51 (4):400-411. doi: 10.1177/0047287511426338.

Holtorf, Cornelius. 2007. Archaeology is a brand!: The meaning of archaeology in contemporary popular culture. Oxford: Archaeopress.

Ilbery, Brian, and Gunjan Saxena. 2011. "Integrated rural tourism in the English-Welsh cross-border region: An analysis of strategic, administrative and personal challenges." Regional Studies 45 (8):1139-1155.

INE. 2014. Statistical Yearbook of Alentejo Region 2013. Lisbon: Instituto Nacional de Estatística, I.P.

Iordache, Carmen, Iuliana Ciochina, and Mihaela Asandei. 2010. "Clusters: tourism activity increase competitiveness support." Theoretical and Applied Economics 17 (5):99-112. 
Jackson, J., and P. Murphy. 2002. "Tourism destinations as clusters: analytical experiences from the New World." Tourism and Hospitality Research 4:36-52.

Jamal, Tazim B., and Donald Getz. 1995. "Collaboration theory and community tourism planning." Annals of Tourism Research 22 (1):186-204. doi: 10.1016/0160-7383(94)00067-3.

Kasemir, Bernd, Carlo C. Jaeger, and Jill Jager. 2003. "Citizen participation in sustainability assessments." In Public Participation in Sustainability Science: a Handbook, edited by Bernd Kasemir, Jill Jager, Carlo C. Jaeger and Matthew T. Gardner, 3-36. Cambridge: Cambridge University Press.

Komppula, Raija. 2014. "The role of individual entrepreneurs in the development of competitiveness for a rural tourism destination - A case study." Tourism Management 40 (0):361-371. doi: 10.1016/j.tourman.2013.07.007.

Lastra-Anadón, C., J. N. Dias, M. D. Toribio, R. Minguela, and R. F. Aguilera. 2011. The Andalucía tourism cluster.

Le Blanc, Antoine. 2010. "Cultural districts, a new strategy for regional development? The South-East Cultural District in Sicily." Regional Studies 44 (7):905-917. doi: 10.1080/00343400903427936.

Lindroth, Kaija, Jarmo Ritalahti, and Tuovi Soisalon-Soininen. 2007. "Creative Tourism in Destination Development." Tourism Review 62 (3-4):53-58.

McGehee, Nancy Gard, Seungwoo Lee, Teresa L. O'Bannon, and Richard R. Perdue. 2010. "Tourism-related Social Capital and Its Relationship with Other Forms of Capital: An Exploratory Study." Journal of Travel Research 49 (4):486-500. doi: 10.1177/0047287509349271.

Menzel, Max-Peter, and Dirk Fornahl. 2010. "Cluster life cycles-dimensions and rationales of cluster evolution." Industrial and Corporate Change 19 (1):205-238. doi: 10.1093/icc/dtp036.

Michael, Ewen J., ed. 2007. Micro Clusters and Networks: The growth of Tourism. Oxford: Elsevier.

Monitor Company. 1994. Construir as vantagens competitivas de Portugal [Building Portugal's competitive advantages]. Lisbon: Forum para a Competitividade.

Nordin, Sara. 2003. Tourism clustering and innovation. Ostersund: European Tourism Research Institute.

Novelli, Marina, Birte Schmitz, and Trisha Spencer. 2006. "Networks, clusters and innovation in tourism: A UK experience." Tourism Management 27 (6):1141-1152. doi: 10.1016/j.tourman.2005.11.011.

OECD. 2014. Tourism and the creative economy. Paris: OECD.

Pearce, Douglas G. 2014. "Toward an Integrative Conceptual Framework of Destinations." Journal of Travel Research 53 (2):141-153. doi: 10.1177/0047287513491334.

Pera, Rebecca. 2014. "Empowering the new traveller: storytelling as a co-creative behaviour in tourism." Current Issues in Tourism:1-8. doi: 10.1080/13683500.2014.982520.

Pine, B. Joseph, and James H. Gilmore. 1999. The experience economy: Work is theatre \& every business a stage. Boston: Harvard Business School Press.

Plummer, Ryan, David Telfer, Atsuko Hashimoto, and Robert Summers. 2005. "Beer tourism in Canada along the Waterloo-Wellington Ale Trail." Tourism Management 26 (3):447-458. doi:

10.1016/j.tourman.2003.12.002.

Porter, Michael E. 1998. "Clusters and the new economics of competition." Harvard Business Review 76 (6):77-+.

Porter, Michael E. 2000. "Location, competition, and economic development: Local clusters in a global economy." Economic Development Quarterly 14 (1):15-34. doi: 10.1177/089124240001400105.

Prentice, Richard, and Vivien Andersen. 2007. "Creative tourism supply: Creating culturally empathetic destinations." In Tourism, creativity and development, edited by Greg Richards and Julie Wilson, 89106. London: Routledge.

Renfrew, Colin, and Paul G. Bahn. 2012. Archaeology: Theories, Methods and Practice. London: Thames \& Hudson.

Richards, Greg. 2011. "Creativity and tourism: The state of the art." Annals of Tourism Research 38 (4):12251253. doi: 10.1016/j.annals.2011.07.008.

Richards, Greg, and Julie Wilson. 2006. "Developing creativity in tourist experiences: A solution to the serial reproduction of culture?" Tourism Management 27 (6):1209-1223. doi: 10.1016/j.tourman.2005.06.002.

Saldaña, Johnny. 2013. The coding manual for qualitative researchers. 2nd ed. London: Sage. 
Saturnino, Antonio. 2009. "Cultural heritage, sustainable tourism and economic development: a proposal for Southern Italy." In Cultural Tourism and Sustainable Local Development edited by L. F. Girard and P. Nijkamp, 95-107. Surrey: Ashgate.

Saxena, Gunjan, and Brian Ilbery. 2008. "Integrated rural tourism a border case study." Annals of Tourism Research 35 (1):233-254. doi: 10.1016/j.annals.2007.07.010.

Spencer, Gregory M., Tara Vinodrai, Meric S. Gertler, and David A. Wolfe. 2009. "Do clusters make a difference? Defining and assessing their economic performance." Regional Studies 44 (6):697-715. doi: 10.1080/00343400903107736.

Tallman, Stephen, Mark Jenkins, Nick Henry, and Steven Pinch. 2004. "Knowledge, clusters, and competitive advantage." Academy of Management Review 29 (2):258-271.

Tan, Siow-Kian, Shiann-Far Kung, and Ding-Bang Luh. 2013. "A model of 'creative experience' in creative tourism." Annals of Tourism Research 41:153-174. doi: 10.1016/j.annals.2012.12.002.

Turismo de Portugal. 2007. Plano Estratégico Nacional do Turismo [National Strategic Plan for Tourism]. Lisbon: Turismo de Portugal, I.P.

Turismo de Portugal. 2013. Plano Estratégico Nacional do Turismo: revisão e objectivos 2013-2015 [National Strategic Plan for Tourism: review and goals 2013-2015]. Lisbon: Turismo de Portugal, I.P.

Valera, António Carlos. 2013. "Recintos de fossos da Pré-História recente em Portugal [Ditched enclosures from recent Pre-history in Portugal]." Almadan 18 (II):93-110.

VERBI Software. 2012. MAXQDA software for qualitative data analysis. Berlin, Germany: Consult: Sozialforschung $\mathrm{GmbH}$.

Waitt, Gordon. 2000. "Consuming heritage perceived historical authenticity." Annals of Tourism Research 27 (4):835-862. doi: 10.1016/s0160-7383(99)00115-2.

Wang, Dan, and John Ap. 2013. "Factors affecting tourism policy implementation: A conceptual framework and a case study in China." Tourism Management 36:221-233. doi: 10.1016/j.tourman.2012.11.021.

Weidenfeld, Adi, R. Butler, and Allan Williams. 2010. "Clustering and Compatibility between Tourism Attractions " International Journal Of Tourism Research 12:1-16.

Welford, R., and B. Ytterhus. 1998. "Conditions for the transformation of eco-tourism into Sustainable tourism." European Environment 8:193-201.

Willems, Willem. 2008. "Archaeological resource management and preservation." Preserving Archaeological Remains In Situ Conference, Amsterdam.

Wilson, Suzanne, Daniel R. Fesenmaier, Julie Fesenmaier, and John C. Van Es. 2001. "Factors for Success in Rural Tourism Development." Journal of Travel Research 40 (2):132-138. doi:

$10.1177 / 004728750104000203$. 